\title{
Cellular and topochemical characteristics of secondary changes in bark tissues of beech (Fagus sylvatica)
}

\author{
Peter Prislan ${ }^{1, *}$, Gerald Koch ${ }^{2}$, Uwe Schmitt ${ }^{2}$, Jožica \\ Gričar $^{3}$ and Katarina Čufar ${ }^{1}$ \\ ${ }^{1}$ Department of Wood Science and Technology, \\ Biotechnical Faculty, University of Ljubljana, Ljubljana, \\ Slovenia \\ ${ }^{2}$ Institute for Wood Technology and Wood Biology, Johann \\ Heinrich von Thünen- Institute (vTI), Hamburg, Germany \\ ${ }^{3}$ Slovenian Forestry Institute, Ljubljana, Slovenia \\ * Corresponding author. \\ Department of Wood Science and Technology, Biotechnical \\ Faculty, University of Ljubljana, Rožna dolina, Cesta VIII/34, \\ SI-1000 Ljubljana, Slovenia \\ Phone: + 386-1-3203648 \\ Fax: + 386-1-4235035 \\ E-mail: peter.prislan@bf.uni-lj.si
}

\begin{abstract}
Anatomical and histometrical investigations were carried out on bark tissues (non-collapsed and collapsed phloem, and periderm) of beech (Fagus sylvatica L.) trees growing at a forest site near Ljubljana, Slovenia (400 m a.s.1.). Secondary changes in bark, especially sclereid formation and lignification, were followed at cellular and sub-cellular levels by light microscopy (LM), UV microspectrophotometry (UMSP), and transmission electron microscopy (TEM). The average width of the whole bark was $5960 \mu \mathrm{m}$; non-collapsed phloem on average occupied $4 \%$, collapsed phloem $89 \%$, and periderm $7 \%$ of the bark. Secondary changes in mature phloem were characterized by a collapse of sieve tubes, inflation of axial parenchyma, and development of sclereids. The percentage of sclereid areas and the stage of their development elevated with increasing distance from the cambium. The most pronounced increment in the sclereid proportion was observed in the second- and third-fifth of the bark. Sclereid cell walls were thick and poly-lamellated and had similar spectral characteristics but distinctly higher UV absorbance values than xylem fibers. By means of a combination of LM, TEM and UMSP techniques, the structure and secondary changes in the bark could be precisely identified.
\end{abstract}

Keywords: bark; beech (Fagus sylvatica); secondary phloem; topochemical analysis; transmission electron microscopy (TEM); UV microspectrophotometry (UMSP).

\section{Introduction}

The structure of bark is very complex and varies considerably among different tree species in terms of its cellular and chemical composition, as well as physical properties. Utili- zation of bark, despite great possibilities, is still very limited. In recent years, for instance, the use of bark as a biofuel for thermal energy has increased (Mészáros et al. 2004; Obernberger et al. 2006). Bark is also used as raw material to produce composites such as particle boards, hardboards, and MDF boards (Xing et al. 2007). However, the potential for its efficient utilization is still not exploited because of economic constraints.

Bark includes all outer tissues in tree stems, i.e., branches and roots that are produced by two secondary lateral meristems: vascular cambium (cambium) and cork cambium (phellogen). Bark tissues derived from vascular cambium are called secondary phloem (e.g., Strasburger 1983; Trockenbrodt 1990).

Beech is one of the so-called "peridermal trees", which permanently retain their first and the only periderm (Holdheide 1951). Additional periderms, which separate the outer bark tissues and slough them off the tree, are not formed in beech. Consequently, it does not have dead outer bark (rhytidome). Trees containing only one periderm have developed "space saving strategies", such as the absence of phloem fibers and a distinctive collapse of sieve tubes with ongoing compression over time (Holdheide 1951).

Several studies on bark tissues have focused on the sieve tubes and companion cells in the non-collapsed part of the phloem, which is physiologically very important for the survival of trees. The sieve tubes are responsible for long distance translocation of products of photosynthesis from the leaves to tissues in which growth and storage take place, and also for the transport of other endogenous and foreign macromolecules (Evert 1982, 2006; Oparka and Robert 1999; Taiz and Zeiger 2006).

In general, sieve tubes remain functional for only one year and then collapse. This process is obvious in some species, whereas in others the sieve tubes only lose their functionality but may remain morphologically unchanged (apparently noncollapsed) for years. Tucker and Evert (1969), for instance, studied phloem formation in Acer negundo L. They found that the first indication of cessation of functioning of the sieve elements was the accumulation of callose on the sieve plates and lateral sieve areas, followed by the disappearance or degradation of cell contents. Concomitantly, sieve elements and companion cells lost their turgor pressure and most underwent partial collapse. At the beginning of cambial activity in the following spring, these sieve elements were almost completely compressed. Similar findings were also presented by Davis and Evert (1968) for Populus tremuloides Michx. On the other hand, it was found that sieve elements in conifers could function for several years (Holdheide 1951). 
The collapse of sieve cells represents the onset of secondary changes, which, according to Esau (1969), are divided into four stages: (1) breakdown of sieve elements; (2) dilatation of tissues as a consequence of enlargement and division of axial and ray parenchyma cells; (3) sclerification of parenchyma cells; and (4) accumulation of crystals in the lumina of some cells (Evert 2006). The dilatation process has been described as a tangential expansion or expanding growth of axial and ray parenchyma. Parenchyma cells divide in a tangential direction in order to adjust the phloem area to the increasing circumference of the tree (Holdheide 1951; Whitmore 1962; Evert 2006).

Sclerification of non-conducting phloem is almost always associated with dilatation growth. Both axial and ray parenchyma cells may become sclerified (Evert 2006). Holdheide (1951) reported that sclereids usually appear in two regions in non-collapsed phloem. They start to form in areas of compressed sieve tubes and in dilatation tissue. The timing of sclereid formation differs among tree species. Davis and Evert (1968) observed that ray parenchyma cells in P. tremuloides underwent sclerification one to two years after the cessation of functioning of sieve tubes. Holdheide (1951), however, never observed sclereids in phloem growth rings younger than four to five years in beech.

Only a few basic studies on beech (Fagus sylvatica L.) bark structure have been published, including topics such as general bark anatomy (Holdheide 1951; Whitmore 1963), histometry of non-collapsed phloem (Trockenbrodt 1990; Dustin et al. 1994; Vollenweider et al. 1994), and the ultrastructure of sclereid cell walls in collapsed phloem (Parameswaran 1975; Parameswaran and Sinner 1979). There is only a little knowledge about developmental processes in beech bark and whether (and to what degree) these processes are linked to environmental influence.

To close this gap, anatomical and histometrical investigations of bark tissues of beech have been carried out. The topochemistry of the bark tissue will be studied the first time at sub-cellular level by means of scanning UV microspectrophotometry (UMSP). The working hypothesis was that the advanced UMSP method will permit the direct imaging of the topochemical distribution of lignin and phenolic extractives in the individual cell types and cell wall layers of the bark.

The specific goals of the study were:

- to analyze the width and structure of bark, including noncollapsed and collapsed phloem and periderm in beech;

- to observe secondary changes in older phloem tissue at cellular and sub-cellular levels;

- to follow the formation of sclereids and to define the lignin content in their cell walls by means of UMSP and TEM.

\section{Materials and methods}

\section{Material}

Tissue samples (outer xylem, cambium, bark) were collected from living beech ( $F$. sylvatica) trees aged over 100 years, growing at a forest site near Ljubljana (approx. $46^{\circ} \mathrm{N}, 14^{\circ} 40^{\prime} \mathrm{E}, 400 \mathrm{~m}$ a.s.l.) on
10 October 2008. Intact tissue samples were collected from 18 trees according to the method described by Prislan et al. (2009). The samples, measuring $25 \times 10 \times 10 \mathrm{~mm}^{3}(1 \times \mathrm{r} \times \mathrm{t})$, were fixed in formalin-ethanol-acetic acid solution (FEA) immediately after their removal from the trees. All samples from all 18 trees were checked by LM. Six of them were selected for UMSP and TEM investigations.

\section{Light microscopy (LM)}

The samples were reduced to $5 \times 5 \times 15 \mathrm{~mm}^{3}(1 \times \mathrm{r} \times \mathrm{t})$ blocks for LM. They were embedded in paraffin with a Leica TP 1020-1 tissue processor (Leica Microsystems, Wetzlar, Germany) (Rossi et al. 2006). Cross and radial sections ( $12 \mu \mathrm{m}$ thick) were cut with a Leica RM 2245 rotary microtome (Leica Microsystems, Wetzlar, Germany), stained with water solution of safranine (Merck, Darmstadt, Germany) $(0.04 \%)$ and astra blue (Sigma-Aldrich, Steinheim, Germany) $(0.15 \%)$, embedded in Euparal and examined with a Nikon Eclipse E800 microscope (Nikon, Tokyo, Japan) (transmission and polarized light modes) (e.g., Schmitt et al. 2003; Gričar 2007). The image analysis system NIS Elements 3.0 (Nikon, Tokyo, Japan) was used for histometrical measurements. The widths of the whole bark, non-collapsed phloem (early and late phloem), periderm and the last formed xylem growth ring were measured to evaluate the correlation between xylem and phloem growth ring widths, as well as between the widths of the phloem growth rings and periderm. In addition, the dimensions (tangential diameter) of early and late phloem sieve tube lumina and differences among them were evaluated in the growth rings of non-collapsed phloem. Measurements of the sclereid area (SC\%) in the bark related to the distance from the cambium were also performed. For this purpose, the bark was divided into five equal parts (each with area $\mathrm{A}$ ) and the sclereid area $\left(\mathrm{SC}_{\mathrm{A}}\right)$ was evaluated in each of them: $S C \%=\left(S C_{A} * 100\right) / A$. The dimensions (length, cell wall thickness and perimeter) of developing and completely formed sclereids were also evaluated.

\section{Celluar UV by microspectrophotometry (UMSP)}

Parallel sample blocks measuring $3 \times 2 \times 2 \mathrm{~mm}^{3}(1 \times \mathrm{r} \times \mathrm{t})$ from six representative trees were prepared for UMSP and TEM. They were dehydrated in a graded series of ethanol $(70 \%, 90 \%, 95 \%$ and $100 \%$ ) and water-free acetone, and then embedded in Spurr's epoxy resin (SPI Supplies, USA) (Spurr 1969). For UMSP, the embedded blocks were trimmed to provide a face of approxiately $0.5 \mathrm{~mm}^{2}$. Semithin transverse sections $(1 \mu \mathrm{m})$ were cut with an ultramicrotome Ultracut E (Reichert-Jung, Wetzlar, Germany) equipped with a diamond knife, transferred to quartz microscope slides immersed in a drop of non UV-absorbing glycerine (Zeiss, Germany) and covered with a quartz cover slip.

UMSP instrument: ZEISS UMSP 80 (Zeiss, Germany), equipped with an immersion ultrafluar lens 1:32; for details see Koch and Kleist (2001) and Koch and Grünwald (2004). The instrument was also equipped with a scanning stage allowing the determination of image profiles at a constant wavelength with the scan programme APAMOS $^{\circledR}$ (Zeiss, Germany). Lignin was detected at $278 \mathrm{~nm}$; see Koch and Kleist (2001). The scan programme digitized rectangular fields with a local geometric resolution of $0.25 \mu \mathrm{m} \times 0.25 \mu \mathrm{m}$ and yielded a photometric resolution of 4096 grayscale levels, which were converted into 14 basic colors to visualize the absorbance intensities. The scans were depicted as two dimensional (2D) or three dimensional (3D) image profiles, including a statistical evaluation (histograms) of the UV-absorbance. Photometric point-bypoint measurements were also performed with a spot size of $1 \mu \mathrm{m}^{2}$ between 240 and $700 \mathrm{~nm}$ in $1 \mathrm{~nm}$ steps. The program LAMWIN ${ }^{\circledR}$ 
(Zeiss, Germany) was used, which records the spectra of the lignified cell walls. The measurements were automatically repeated 50 times for each point analysis.

\section{Transmission electron microscopy (TEM)}

Samples were embedded as usual in Spurr's epoxy resin. Ultrathin transverse sections (80-100 nm thick) were cut with an ultramicrotome Ultracut E (Reichert-Jung, Wetzlar, Germany) as described by Gričar (2007) and stained with $\mathrm{KMnO}_{4}$ according to Donaldson (1992). Philips CM 12 TEM (Philips, Eindhoven, The Netherlands) was used at accelerating voltages of 40 or $60 \mathrm{kV}$ to enhance contrast.

\section{Results and discussion}

\section{Structure and width of beech bark}

Bark tissue in beech consists of non-collapsed and collapsed phloem and periderm (Figure 1a). The non-collapsed phloem is composed of sieve tubes, companion cells and parenchyma cells (axial and ray parenchyma) but it does not contain phloem fibers (Figure 1a,b). Just as in xylem, the rays in phloem are of two sizes: narrow (2-4 cells wide) and wide (above 10 cells wide). The cellular structure can only be clearly recognized in the last formed phloem ring and only the sieve tubes near the cambium provide conduction. Early and late phloem can also be recognized in the youngest non-collapsed phloem growth ring (Figure 1b). The sieve tubes of early phloem are characterized by large lumina $(52.8 \pm 2.8 \mu \mathrm{m})$ and they are separated from late phloem by a tangential band of axial parenchyma. The sieve tubes of late phloem have about two times smaller diameters $(30.1 \pm 1.9 \mu \mathrm{m})$. In noncollapsed phloem, early phloem occupied $2 / 3$ of the youngest phloem growth ring and the width of the late phloem increased with increasing ring width (Table 1). Contrary, Holdheide (1951) and Vollenweider et al. (1994) did not find differences in the diameters of early and late phloem sieve tubes. Vollenweider et al. (1994) took samples from trees in winter (January and February), and at that time, according to our observations, the early phloem sieve tubes of the youngest phloem ring are already subjected to secondary changes and collapse. The sieve tubes collapse at the end of the vegetation period in which they were formed, so measurements conducted in late winter may include only late phloem of the last formed phloem ring.

Older phloem tissue suffers secondary changes. As the sieve cells lose their turgor, they cease to conduct, collapse and die. However, the surrounding parenchyma cells remain alive much longer and undergo several phases of secondary change, which lead to the development of various types of cells, such as sclereids. Sclereids therefore derive ontogenetically from parenchyma cells as already described by Holdheide (1951) and Trockenbrodt (1990). Their abundance increases towards the older, outer parts of the bark. The major part of beech bark is formed by vascular cambium; only the periderm is produced by phellogen. Periderm (composed of phelloderm, phellogen-cork cambium and phellemcork) forms the outermost part of beech bark. As pointed

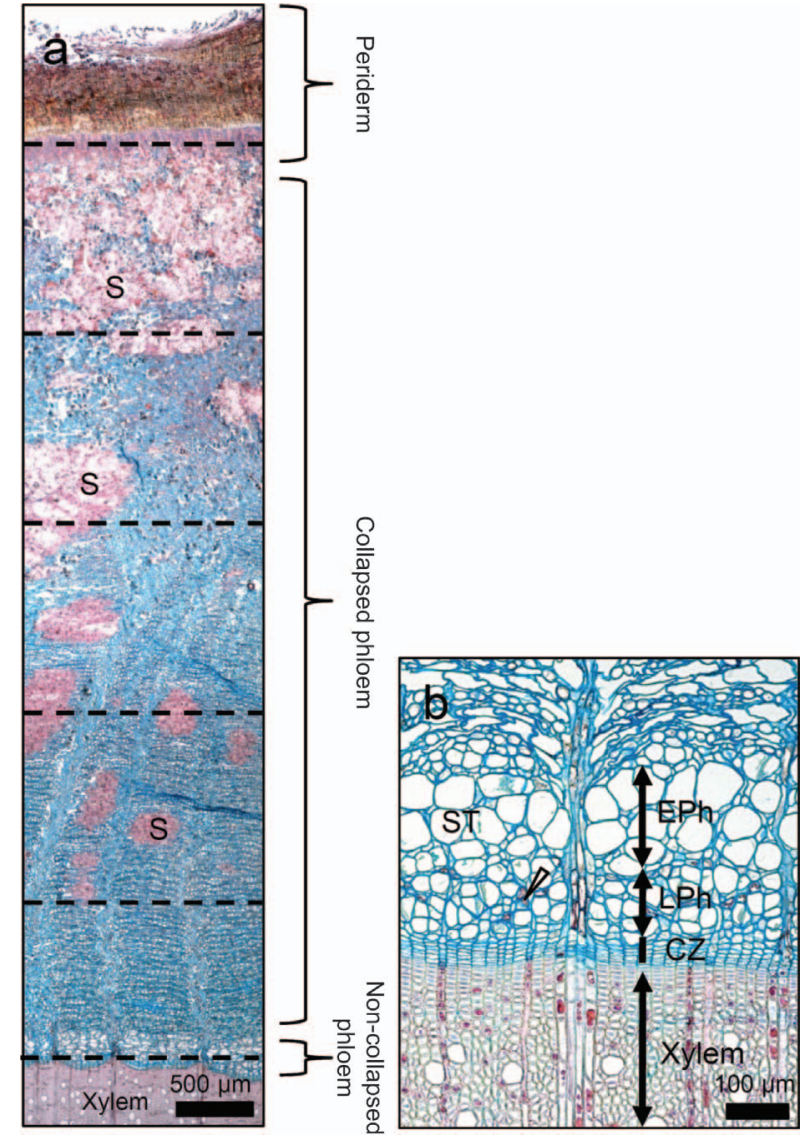

Figure 1 Beech bark: (a) entire bark consisting of non-collapsed and collapsed phloem and periderm; phloem is divided into five equal parts to evaluate the proportion of sclereids $(\mathrm{S})$ in relation to the distance from the cambium. (b) One growth ring in noncollapsed phloem consisting of early phloem (EPh) and late phloem $(\mathrm{LPh})$. Sieve tubes $(\mathrm{ST})$, cambium zone $(\mathrm{CZ})$, axial parenchyma (arrowhead).

out, beech normally has only one superficial periderm and, consequently, no dead outer bark (rhytidome). This is the reason why the surface of the bark remains smooth even in very old trees.

The bark of the sampled beech trees was on average $5960.0 \pm 847.9 \mu \mathrm{m}$ wide. Non-collapsed phloem on average occupied $224.2 \pm 70.1 \mu \mathrm{m}$ (4\% of the bark), collapsed phloem $5278.6 \pm 662.1 \mu \mathrm{m}(89 \%)$ and periderm $453.2 \pm 223.7$ $\mu \mathrm{m}(7 \%)$. The proportion of collapsed tissue increases with increasing bark width. The width of the periderm shows the highest variation among the sampled trees $(\mathrm{RSD}=49.3 \%)$. Furthermore, a weak but statistically significant correlation was found between the width of the periderm and collapsed phloem $\left(\mathrm{R}^{2}=0.499, \mathrm{P}<0.05, \mathrm{~F}=5.31\right)$.

For comparison, the widths of the latest formed xylem increments were measured to obtain information on cambial production on the xylem and phloem sides in the same vegetation period. The average width of the xylem increment was $2492.2 \pm 1233.9 \mu \mathrm{m}$ and the phloem increment was $224.2 \pm 70.1 \mu \mathrm{m}$; the cambium on average produced 11.1 times more xylem than phloem. No correlation was found 
Table 1 Histometrical characteristics of phloem tissues in 18 beech trees.

\begin{tabular}{lcc}
\hline \multicolumn{1}{c}{ Tissue and measured parameter } & Dimensions $(\mu \mathrm{m})$ & Proportion $(\%)$ \\
\hline Bark width & $5960.0 \pm 847.9$ & $4 \%$ of the bark \\
Non-collapsed phloem width & $224.2 \pm 70.1$ & $89 \%$ of the bark \\
Collapsed phloem width & $5278.5 \pm 662.1$ & $7 \%$ of the bark \\
Periderm width & $453.2 \pm 223.7$ & \\
Xylem growth ring 2008 width & $2492.2 \pm 1233.9$ & \\
Early phloem width & $147.6 \pm 13.4$ & $61 \%$ of the non-collapsed phloem growth ring \\
Late phloem width & $95.6 \pm 10.8$ & $39 \%$ of the non-collapsed phloem growth ring \\
& & \\
Early sieve tubes diameter & $52.8 \pm 2.8$ & \\
Late sieve tubes diameter & $30.1 \pm 1.9$ & \\
& & \\
Diameter of axial parenchyma cells & $18.6 \pm 2.5$ & \\
Length of axial parenchyma cells & $60.1 \pm 5.7$ & \\
Cell wall thickens of axial parenchyma cells & $5.4 \pm 0.3$ & \\
Sclereid cell wall thickness & $13.0 \pm 1.0$ & \\
\end{tabular}

between xylem and phloem ring widths $\left(\mathrm{R}^{2}=0.066\right)$, nor between xylem and early phloem widths $\left(\mathrm{R}^{2}=0.0014\right)$. On the other hand, the correlation between the width of the xylem ring and late phloem is weak but statistically significant $\left(\mathrm{R}^{2}=0.17, \mathrm{P}<0.05, \mathrm{~F}=4.72\right)$.

The width of non-collapsed phloem can be a strong indicator of the physiological condition of the tree. Holdheide (1951) speculated about the influence of environment on phloem growth ring widths. The author assumed that phloem growth rings are more or less constant from year to year, unless environmental conditions are extremely unfavorable. In such cases, the phloem growth ring cannot develop completely, which results in a reduced width and portion of late phloem. Similarly, Gričar and Čufar (2008) and Gričar et al. (2009), who investigated phloem and xylem increments of Abies alba Mill. and Picea abies (L.) Karst. found that the cambium produced five to 12 times more xylem cells than phloem ones. They presumed that phloem formation is less dependent on environmental factors and more internally driven than xylem formation.

\section{Secondary changes in phloem at cellular and sub-cellular levels}

Secondary changes in older phloem of beech were characterized by the collapse of sieve tubes, inflation of axial parenchyma and development of sclereids. Sclereids in younger phloem were grouped in radial bands and in older phloem (close to the periderm) in tangential bands, in a way as described by Holdheide (1951). A positive correlation between the sclereid area and the age of the tissue was confirmed (Figure 1a). The proportion of sclereids increased from the cambium towards the periderm and considerable differences among the sampled trees could be observed. The youngest fifth of the phloem contained on average $5 \%$ of sclereids (Figure 1a). In the second fifth of the bark, the percentage increased to $17 \%$, in the third it was $20-25 \%$, in the fourth $20-30 \%$ and in the fifth (the oldest part of the bark) $35 \%$. Therefore, the most pronounced increase in scler- eid proportion was observed in the second and third fifths of the bark. This may be explained by the fact that the majority of the secondary changes in the bark occurred in the transition zone from non-collapsed to collapsed phloem.

Secondary changes that occur in older phloem differ among tree species. For instance, Tucker and Evert (1969) described secondary changes in A. negundo and Davis and Evert (1968) in P. tremuloides and found that sclerification of phloem parenchyma cells progressively increased with the age of cells. Sclereids were thus more abundant in older tissues. In Robinia pseudoacacia L. however, scattered patches of sclereids sometimes occur near the periderm but rarely in other parts of the secondary phloem (Derr and Evert 1967).

However, not only the percentage of sclereid area but also the stage of their development (i.e., lignification and deposition of phenolic extractives) increased with longer distances from the cambium. UMSP analysis of non-collapsed phloem shows no presence of aromatic compounds in this region; absorbances were therefore low $\left(\mathrm{A}_{278}\right.$ 0.09-0.16) (Figure 2a,f). Aromatic compounds only appeared locally probably representing lignin precursors in phloem. The absorbance values were also very low in the youngest part of the collapsed phloem (Figure 2b,g), which consists of collapsed sieve tubes, companion cells, and inflated axial parenchyma cells.

Tangential layers of darker colored crushed cell walls of compressed sieve tubes and lighter colored inflated axial parenchyma are clearly visible in collapsed phloem (Figure 2b). UV-measurements revealed locally increased absorbance values (around $\mathrm{A}_{278} 0.09$ and 0.16 ), probably indicating the presence of lignin precursors and other aromatic compounds in these regions (Figure 2g). Cell wall formation and lignification of inflated axial parenchyma cells and thus their transformation into sclereids apparently start here. TEM observations show thin walled axial parenchyma cells with degraded protoplasm in their lumina (Figure 3a). They are surrounded by collapsed sieve tubes, which stained darker due to a higher electron density. 


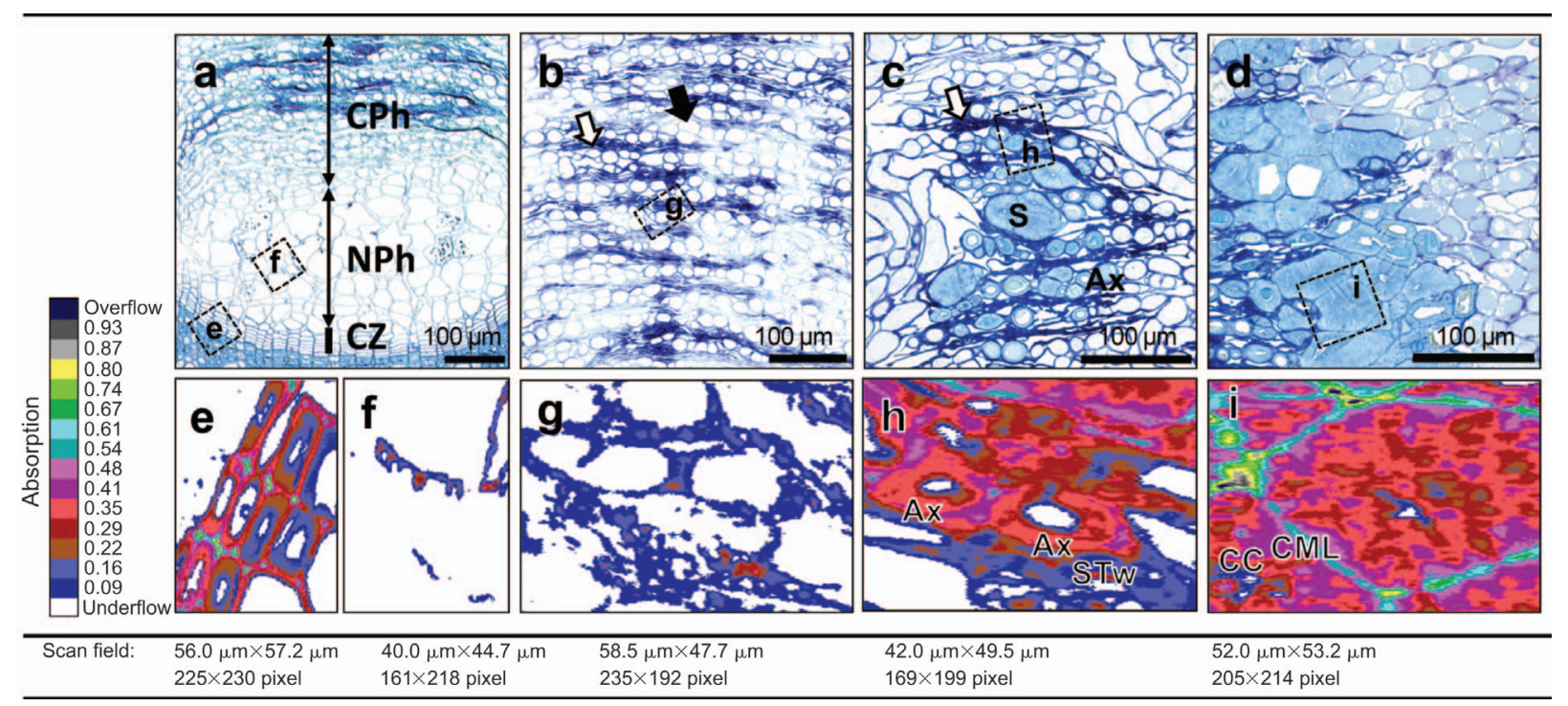

Figure 2 Secondary changes and sclereid formation in beech bark. (a-d) Light microscopy (LM), transverse sections of different parts of the phloem; (a) cambium zone $(\mathrm{CZ})$ and non-collapsed phloem $(\mathrm{NPh})$, (b) collapsed phloem $(\mathrm{CPh})$ in the first fifth of the bark containing compressed sieve tubes (white arrow) and inflated axial parenchyma (black arrow), (c) group of thick walled axial parenchyma cells (Ax) and sclereids (S) in the third fifth of the bark, (d) completely formed sclereid in the last fifth of the bark and. The frames on the LM pictures indicate the area of scanning fields. (e-i) Images of UV microspectrophotometry (UMSP) analysis showing absorbance values of aromatic compounds in (e) xylem tissue and CZ, (f) NPh with non-collapsed sieve tubes and Ax, (g) sieve tubes (STw) and inflated Ax, (h) groups of thick walled Ax and (i) completely formed $\mathrm{S}$.

In the second and third fifths of the bark, axial parenchyma cells with thicker walls $(5.4 \pm 0.4 \mu \mathrm{m})$ are visible, which are adjacent to fully developed sclereids (Figure 2c). Their cell walls revealed distinctly higher absorbance values, in the range of $\mathrm{A}_{278}$ 0.16-0.22 or even higher, $\mathrm{A}_{278} 0.35$ (Figure 2h). Morphologically, they could be clearly distinguished from sclereids, which were larger and had thicker cell walls $(13.0 \pm 1.0 \mu \mathrm{m})$ and smaller lumina (Figures $2 \mathrm{c}$ and $3 \mathrm{~b})$. In radial sections of the tissues, the parenchyma cells are on average $60.1 \pm 5.7 \mu \mathrm{m}$ long, with diameters of $18.6 \pm 2.5$ $\mu \mathrm{m}$. The amount of such thick-walled parenchyma cells decreases with longer distances from the cambial zone, whereas the amount of sclereids increases.

The groups of sclereids become larger and more frequent with increasing distance from the cambial zone, especially in the vicinity of the rays. The absorbance values of sclereid cell walls in the middle part of the bark amounted to $\mathrm{A}_{278}$ 0.35-0.41 in the S2 layer, $\mathrm{A}_{278} 0.67-0.74$ in the compound middle lamella (CML) and $\mathrm{A}_{278} 0.80$ in the cell corners (CC).

The cell wall structure of the sclereids proved to be similar to that of xylem fibers. It consists of CML and primary wall and the secondary wall consists of S1 and S2 layers, with a typically poly-lamellated structure (Figure 3c). This is in agreement with the previous observations of Parameswaran (1975).

The lignin content varies in different layers of fully developed sclereid walls. The highest absorbances were detected in the $\mathrm{CC}\left(\mathrm{A}_{278} 0.67-0.74\right)$, slightly lower in the CML $\left(\mathrm{A}_{278}\right.$ $0.54-0.61)$, and the lowest in the $\mathrm{S} 2$ layer $\left(\mathrm{A}_{278} 0.22-0.41\right)$ (Figures $2 \mathrm{i}$ and 5 ), which is the widest layer of the cell wall. Darker and brighter concentric strands in S2 layers of the cell walls of diversely developed sclereids are visible by LM, but a distribution of absorption values in the form of concentric strands on scanning UMSP images could not be observed (Figure 2i). The cell wall structure of completely formed sclereids in beech bark was similar to that in Entandrophragma candollei Harms, as observed by Parameswaran (1975). However, differences were detected in the absorbance maxima using the improved scanning UMSP technique. The highest absorbance maximum of sclereids at a $278 \mathrm{~nm}$ wavelength measured here, indicating a greater amount of syringyl units of lignin, whereas a shift towards $280 \mathrm{~nm}$ shows a prevalence of guaiacyl units (Fergus and Goring 1970; Musha and Goring 1975; Terashima 2000; Koch and Grünwald 2004). TEM micrographs show that the cell walls of sclereids are perforated with several pits with ramiform canal-like cavities (Figure 3c). Lower absorbance values locally occurred in a radial direction in sclereid cell walls, which may be due to pit canals that have been cut through. The darker and brighter concentric strands were also analyzed by conventional UMSP point measurements. They showed a similar spectral behavior of brighter and darker strands, as previously described by Parameswaran (1975). The author assumed that lamellated structure of sclereid cell walls is mainly a consequence of variously oriented cellulose microfibrils and not of different lignin concentrations.

For comparison, the absorbance values of fully developed xylem cells varied between $\mathrm{A}_{278} 0.35$ in the cell corners (CC) and $\mathrm{A}_{278} 0.09-0.22$ in the secondary cell wall (S2) of beechwood fibers. Absorbance in S2 of the terminal xylem fibers was slightly higher $\left(\mathrm{A}_{278} 0.22-0.29\right)$ (Figure 2e). 

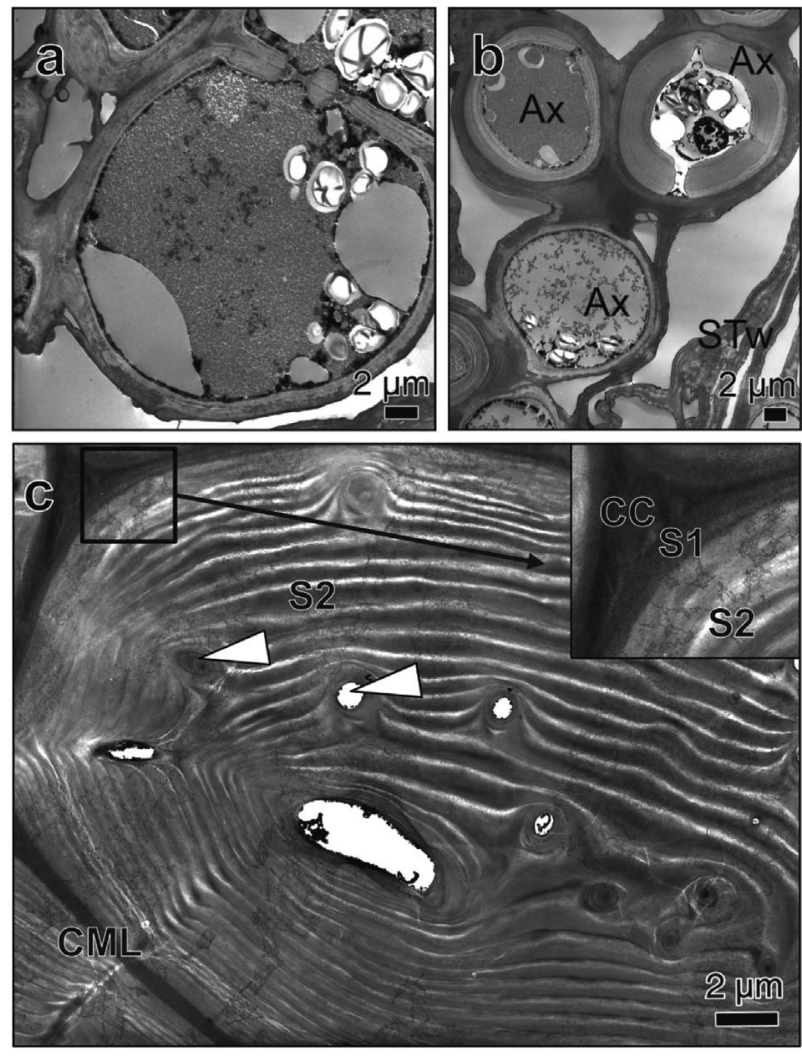

Figure 3 Transmission electron microscopy (TEM) micrographs of transverse sections through (a) Ax in the younger part of bark, (b) thick walled Ax cells in the middle part of the bark and (c) completely formed sclereid with lumen and numerous pits (white arrowheads) without contents (white ones) or filled with high electron density material (dark ones).

CC, cell corner; CML, compound middle lamella; S1 and S2, layers of the sclereid secondary wall.

Topochemical analyses in the periderm, which consists of phellem, phellogen and phelloderm (Figure 4a) reveal: absorbances in phellem cell walls are high (ranging from $\mathrm{A}_{278} 0.48$

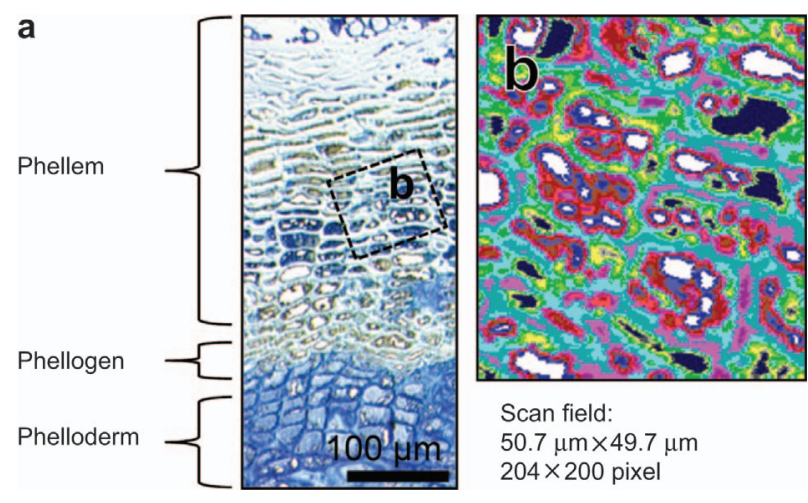

Figure 4 Transverse section of periderm under (a) light microscopy (LM). The frames on the LM picture indicate the area of scanning field for UV microspectrophotometry (UMSP). (b) Image of UMSP analysis showing absorption values of phenolic extractives in phellem. For the color scale see Figure 3.

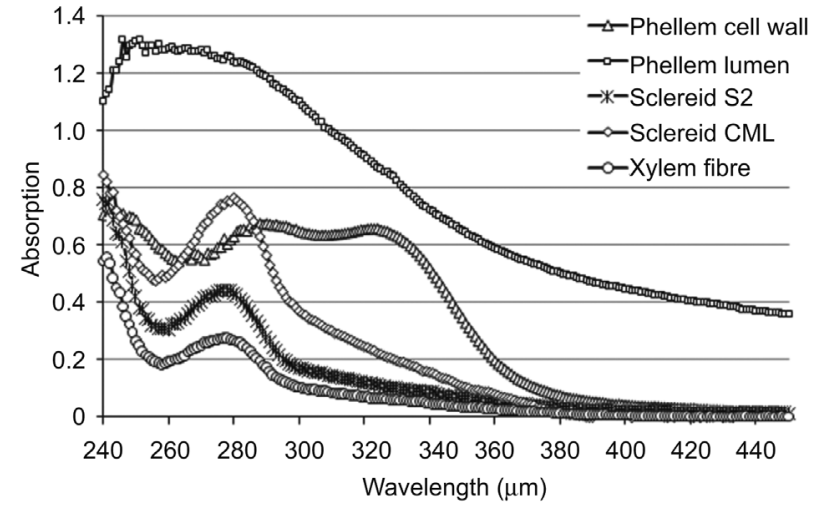

Figure 5 Representative UV absorbance spectra of various morphological regions in the bark; phellem cell wall, phellem cell lumen, sclereid secondary wall (S2), sclereid middle lamella (CML) and xylem fiber secondary wall.

in $\mathrm{S} 2$ to 0.80 in $\mathrm{CC})$ but even higher values $\left(\mathrm{A}_{278}>1.0\right)$ were measured in the phellem cell lumina (Figure $4 \mathrm{~b}$ ). This spectral behavior can be explained by the deposition of phenolic extractives in the lumina of phellem cells. The presence of extractives (tannins) can be distinctly visualized as conglomerations of higher absorbances $\left(\mathrm{A}_{278}>1.0\right)$ compared with the surrounding cell wall layers. These compounds are generally synthesized by parenchyma cells in situ and undergo condensation during secondary changes of the phellem.

Point measurements reveal that the spectral characteristics of the phenolic deposits in the cell lumina and in the cell wall layers of the phellem are different to those of lignin spectra of the sclereids and xylem fiber cell walls (Figure 5). The deposits have higher absorbances (maximum around 1.3) in a wavelength range from 260 to $285 \mathrm{~nm}$ without a specific maximum peak. This can be explained by the presence of chromophoric groups, such as conjugated double bonds attributed to highly condensed phenolics. The higher degree of conjugation stabilizes $\pi-\pi^{*}$ transitions, resulting in elevated absorbances and bands shifted to longer wavelengths (Figure 5). In comparison, the spectra of the S2 and CML of sclereids and xylem fibers show typical absorbance behavior of hardwood lignin (e.g., Fergus and Goring 1970; Takabe et al. 1992; Koch and Kleist 2001; Röder et al. 2004; Lehringer et al. 2008), with a distinct maximum at $278 \mathrm{~nm}$ and a local minimum at about $250 \mathrm{~nm}$. Even a semi-quantitative determination of the local lignin content is feasible, for instance, by a significantly higher absorbance maximum of the CML $\left(\mathrm{A}_{278} 0.8\right)$ as compared to the $\mathrm{S} 2\left(\mathrm{~A}_{278} 0.45\right.$ and $0.25)$. The UV spectra of the phellem cell walls can be clearly distinguished from those of sclereids and xylem fibers. The detected spectra have the first maximum at $283 \mathrm{~nm}$ and a shoulder at $324 \mathrm{~nm}$. The latter can be explained by the presence of conjugated double bonds, for example carbonyl groups of phenolic extractives that are incrusted in the cell walls of the phellem. Similar spectral behavior was described by Koch et al. (2003) for extractive components in the lumina of axial parenchyma in discolored beech wood. 


\section{Conclusions}

The microscopic techniques LM, UMSP and TEM enabled a better understanding of the structure and secondary changes in bark tissues of beech. Early phloem sieve tubes are subjected to secondary changes and collapse already at the end of the vegetation period in which they are formed. The present study is among the first, in which early phloem could be distinguished from late phloem. The majority of secondary changes occurred in the transition zone from non-collapsed to collapsed phloem. The percentage of sclereid area and the stage of sclereid development increased with distance from the cambium and with age. Topochemical analyses of individual cell types of the periderm were also made.

\section{Acknowledgements}

This work was supported by the Slovenian Research Agency, young researchers' program, by programs $\mathrm{P} 4-0015$ and $\mathrm{P} 4-0107$, and by the LLP ERASMUS bilateral agreement between the University of Ljubljana and the University of Hamburg. The authors gratefully acknowledge the help of Jasna Štrus and her team at the Department of Biology, Biotechnical Faculty, University of Ljubljana. We thank Tanja Potsch and Magda Tušek Žnidarič for their immense help in the laboratory.

\section{References}

Davis, J.D., Evert, R.F. (1968) Seasonal development of the secondary phloem in Populus tremuloides. Bot. Gaz. 129:1-8.

Derr, W.F., Evert, R.F. (1967) The cambium and seasonal development of the phloem in Robinia pseudoacacia. Am. J. Bot. 54:147-153.

Donaldson, L.A. (1992) Lignin distribution during latewood formation in Pinus radiata D. Don. IAWA Bull. 13:381-387.

Dustin, I., Vollenweider, P., Hofer, R.M., Hainard, P. (1994) A study of the cambial zone and conductive phloem of common beech (Fagus sylvatica L.) using an image-analysis method. 2. Automated measurement procedure. Trees 9:113-117.

Esau, K. (1969) The Phloem. Encyclopedia of Plant Anatomy. Gebr. Bomtraeger, Berlin, Stuttgart.

Evert, R.F. (1982) Sieve-tube structure relation to function. Bioscience 32:789-795.

Evert, R.F. (2006) Esau's Plant Anatomy. Meristems, Cells, and Tissues of the Plant Body: Their Structure, Function, and Development. Wiley-Interscience, Hoboken, New Jersey.

Fergus, B.J., Goring, D.A.I. (1970) The location of guaiacyl and syringyl lignins in birch xylem tissue. Holzforschung 24:113-117.

Gričar, J. (2007) Xylo- and Phloemogenesis in Silver Fir (Abies alba Mill.) and Norway Spruce (Picea abies (L.) Karst.). Slovenian Forestry Institute, Ljubljana.

Gričar, J., Čufar, K. (2008) Seasonal dynamics of phloem and xylem formation in silver fir and Norway spruce as affected by drought. Russ. J. Plant Physiol. 55:538-543.

Gričar, J., Krže, L., Čufar, K. (2009) Relationship among number of cells in xylem, phloem and dormant cambium in silver fir (Abies alba Mill.) trees of different vitality. IAWA J. 30:121133.
Holdheide, W. (1951) Anatomie mitteleuropäischer Gehölzrinden. In: Handbuch der Mikroskopie in der technik. Ed. Freud, H. Umschau Verlag, Frankfurt am Main, pp. 193-367.

Koch, G., Kleist, G. (2001) Application of scanning UV microspectrophotometry to localise lignins and phenolic extractives in plant cell walls. Holzforschung 55:563-567.

Koch, G., Grünwald, C. (2004) Application of UV microspectrophotometry for the topochemical detection of lignin and phenolic extractives in wood fibre cell walls. In: Wood Fibre Cell walls: Methods to Study their Formation, Structure and Properties. Eds. Schmitt, U., Ander, P., Barnett, J.R., Emons, A.M.C., Jeronimidis, G., Saranpää, P., Stanzl-Tschegg, S. Swedish University of Agricultural Sciences, Uppsala, pp. 119-129.

Koch, G., Bauch, J., Puls, J. (2003) Topochemical characterisation of phenolic extractives in discolored beechwood (Fagus sylvatica L.). Holzforschung 57:339-345.

Lehringer, C., Gierlinger, N., Koch, G. (2008) Topochemical investigation on tension wood fibres of Acer spp., Fagus sylvatica L. and Quercus robur L. Holzforschung 62:255-263.

Mészáros, E., Jakab, E., Várhegyi, G., Szépesváry, P., Marosvölgyi, B. (2004) Comparative study of the thermal behavior of wood and bark of young shoots obtained from an energy plantation. J. Anal. Appl. Pyrol. 72:317-328.

Musha, Y., Goring, D.A.I. (1975) Distribution of syringyl and guaiacyl moieties in hardwoods as indicated by ultraviolet microscopy. Wood Sci. Technol. 9:45-58.

Obernberger, I., Brunner, T., Barnthaler, G. (2006) Chemical properties of solid biofuels - significance and impact. Biomass Bioenerg. 30:973-982.

Oparka, K.J., Robert, T. (1999) Sieve elements and companion cells - traffic control centers of the phloem. Plant Cell 11:739-750.

Parameswaran, N. (1975) Fine-structure of wall of sclereids in some tree barks. Protoplasma 85:305-314.

Parameswaran, N., Sinner, M. (1979) Topochemical studies on the wall of beech bark sclereids by enzymatic and acidic degradation. Protoplasma 101:197-215.

Prislan, P., Koch, G., Čufar, K., Gričar, J., Schmitt, U. (2009) Topochemical investigations of cell walls in developing xylem of beech (Fagus sylvatica L.). Holzforschung 63:482-490.

Röder, T., Koch, G., Sixta, H. (2004) Application of confocal Raman spectroscopy for the topochemical distribution of lignin and cellulose in plant cell walls of beech wood (Fagus sylvatica L.) compared to UV microspectrophotometry. Holzforschung 58:480-482.

Rossi, S., Anfodillo, T., Menardi, R. (2006) Trephor: a new tool for sampling microcores from tree stems. IAWA J. 27:89-97.

Schmitt, U., Grünwald, C., Gričar, J., Koch, G., Čufar, K. (2003) Wall structure of terminal latewood tracheids of healthy and declining silver fir trees in the dinaric region, Slovenia. IAWA J. 24:41-51.

Spurr, A.R. (1969) A low viscosity embedding medium for electron microscopy. J. Ultrastruct. Res. 26:31-43.

Strasburger, E. (1983) Lehrbuch der Botanik für Hochschulen Gustav Fischer Verlag, Stuttgart, New York.

Taiz, L., Zeiger, E. (2006) Plant Physiology. Sinauer Associates, Sunderland, Massachusetts.

Takabe, K., Miyauchi, S., Tsunoda, R., Fukazawa, K. (1992) Distribution of guaiacyl and syringyl lignins in Japanese Beech (Fagus-Crenata) - Variation within an annual ring. IAWA Bull. 13:105-112.

Terashima, N. (2000) Formation and ultrastructure of lignified plant cell walls. In: New Horizons in Wood Anatomy. Eds. Kim, Y.S. Chonnam National University Press, Kwangju, pp. 169-180. 
Trockenbrodt, M. (1990) Survey and discussion of the terminology used in bark anatomy. IAWA Bull. 11:141-166.

Tucker, C.M., Evert, R.F. (1969) Seasonal development of the secondary phloem in Acer negundo. Am. J. Bot. 56:275-284.

Vollenweider, P., Dustin, I., Hofer, R.M., Vittoz, P., Hainard, P. (1994) A study of the cambial zone and conductive phloem of common beech (Fagus sylvatica L) using an image analysis method.1. Influence of tree age on the structure. Trees 9:106112.

Whitmore, T.C. (1962) Studies in systematic bark morphology. II. General features of bark construction in dipterocarpaceae. New Phytol. 61:208-220.
Whitmore, T.C. (1963) Studies in systematic bark morphology. IV. The bark of beech, oak and sweet chestnut. New Phytol. 62: 161-169.

Xing, C., Deng, J., Zhang, S.Y. (2007) Effect of thermo-mechanical refining on properties of MDF made from black spruce bark. Wood Sci. Technol. 41:329-338.

Received May 24, 2011. Accepted June 8, 2011.

Previously published online July 12, 2011. 